\title{
Prevalence of Allergic Rhinitis based on World Health Organization (ARIA-WHO) questionnaire among Batch 2010 Students of the Faculty of Medicine Universitas Padjadjaran
}

\author{
Fauzi, ${ }^{1}$ Melati Sudiro, ${ }^{2}$ Bony Wiem Lestari ${ }^{3}$ \\ ${ }^{1}$ Faculty of Medicine Universitas Padjadjaran, ${ }^{2}$ Department of Otolaryngology-Head \& Neck \\ Surgery Faculty of Medicine Universitas Padjadjaran/Dr. Hasan Sadikin General Hospital \\ Bandung, ${ }^{3}$ Department of Epidemiology and BiostatisticsFaculty of Medicine Universitas \\ Padjadjaran
}

\begin{abstract}
Background: Allergic rhinitis (AR) is a common disease affecting 5-45\% of Asian population. Although it is not a life-threatening disease, AR significantly hampers the quality of life of the sufferers. The prevalence of AR among adults in Indonesia is still unknown. This study aimed to measure the prevalence of AR among batch 2010 students of the Faculty of Medicine, Universitas Padjadjaran.

Methods: A cross-sectional study was conducted during June-October 2013 involving Indonesian class batch 2010 students of the Faculty of Medicine, Universitas Padjadjaran. The sampling was performed using total sampling approach. The measurement tool used in this study was the Indonesian translation of the Allergic Rhinitis and its Impact on Asthma-World Health Organization (ARIA-WHO) questionnairee. Those who were aware of being diagnosed with AR or had two/more AR defining symptoms in the questionnaire form were considered to have AR. The statistical analysis was conducted by calculating frequencies.

Results: A total of 207 questionnaire forms were adequately filled out and returned. Based on the questionnaire, the prevalence rate of AR was $38.2 \%$. Of the 79 AR cases, $66 \%$ cases involved females. In addition, $54 \%$ of the the AR cases have a parental history of allergic diseases. Nasal obstruction and itchy nose were the most frequent symptoms (90\%), followed by rhinorrhea (89\%), sneezing (82\%), and eye symptoms (62\%). Based on the duration, the majority fell into the intermittent group (91\%); whereas based on severity, the majority was in the moderate-severe group (71\%).

Conclusions: The prevalence rate of AR obtained in this study is within the estimated range of Asian population. [AMJ.2015;2(4):620-5]
\end{abstract}

Keywords: Allergic rhinitis, prevalence, questionnaire

\section{Introduction}

Allergic rhinitis (AR) is a common disease defined as a symptomatic disorder of the nose resulting from IgE-mediated inflammation of the nasal membranes after allergen exposure. ${ }^{1}$ Frequent allergens include pollens, moulds, animal dander, and dust mites. The AR is characterized by rhinorrhea (watery runny nose), sneezing (especially violent and in bouts), nasal obstruction, itchy nose, and usually associated with eye symptoms. ${ }^{1,2}$

The AR can be diagnosed in several steps, consisting of anamnesis, physical examination, and supporting examination. Allergic Rhinitis and its Impact on Asthma-World Health Organization (ARIA-WHO) has developed a questionnaire as a screening tool for AR. ${ }^{1}$ Due to its good validity and high sensitivity, ARIAWHO questionnaire has been used widely for many studies related to AR. ${ }^{3}$ Those with the abovementioned classical symptoms of AR are most likely to be allergic. Physical examination can reveal the outward signs of allergy (e.g. allergic crease, allergic shiners, etc) and structural abnormality of the nasal cavities. Furthermore, supporting examinations may include skin-prick test and/or serum-specific IgE, which can confirm the diagnosis of AR. ${ }^{1}$

The common symptoms of AR often disrupt

Correspondence: Fauzi, Faculty of Medicine, Universitas Padjadjaran, Jalan Raya Bandung-Sumedang Km.21, Jatinangor, Sumedang, Indonesia, Phone: +62 85724030303 Email: drfauzi@live.com 
quality of life including the sleep pattern which may further cause exhaustion, drowsiness, emotional instability, and diminution of performance at the workplace. The AR also has a negative impact on productivity and socioeconomic conditions. According to a survey in the United States, $55 \%$ of 8,267 workers stated that AR symptoms had made them unproductive for 3.6 days per year. ${ }^{4}$ World Allergy Organization (WAO) reported that in the United States alone, the indirect financial loss related to low productivity reached up to $\$ 9.7$ billion in 2005 , whereas the direct financial loss for expenditure on medications and health care provision reached $\$ 11.2$ billion. $^{2}$

The AR patients may develop other comorbidities, some of which include asthma, allergic conjunctivitis, and rhinosinusitis. The comorbidities have always been closely linked with $\mathrm{AR}$, for there are histological and immunological similarities between the upper and lower respiratory tracts. The comorbidities can even be more severe that the disorder and may directly have an unfavorable impact on the quality of life. ${ }^{5}$

Epidemiologically, AR affects $10-30 \%$ of world population and the prevalence is still increasing. ${ }^{2}$ According to the 2008 World Allergy Report ${ }^{6}$, the prevalence of AR in the low and middle income countries within AsiaPacific Region was estimated to be around 5-45\%. Unfortunately, the prevalence rate among adults in Indonesia is still unknown. Meanwhile, it is shown that $64.6 \%$ of AR patients who visited the Department of Otolaryngology-Head \& Neck Surgery, Dr. Hasan Sadikin General Hospital Bandung were between 10 to 29 years old, a relatively productive age group. Besides, it is also found that, based on occupation, $45.1 \%$ of the patients were students.

In line with the above explanation, $\mathrm{AR}$ is a prevalent devastating disorder that affects primarily young adults. The objective of this study was to measure the prevalence of AR among batch 2010 students of the Faculty of Medicine, Universitas Padjadjaran.

\section{Methods}

This study was conducted during JuneOctober 2013 using the cross-sectional method as the study design. The ARIA-WHO questionnaire that had been translated into Indonesian language by an authorized and sworn translator from LIA Language Center and Vocational Training (LBPP LIA) was used. The population of this study was obtained from batch 2010 students of regular class of the Faculty of Medicine Universitas, Padjadjaran. The sampling was total sampling. There were thus a total of 207 respondents invited to participate as the subjects in this study. Moreover, ethical clearance of this study was released by the Health Research Ethics Committee of the Faculty of Medicine, Universitas Padjadjaran/Dr. Hasan Sadikin General Hospital Bandung.

All 207 respondents were asked to fill out the ARIA-WHO questionnaire forms. Informed consent was obtained from all participants. The questionnaires were then screened and those who answered yes to any of the AR defining symptoms were shortlisted. Those who were aware of being diagnosed with AR or those who had two/more AR defining symptoms (rhinorrhea, sneezing, nasal obstruction, and itchy nose) were considered to have AR.

The screened AR cases were subsequently classified based on some commonly observed characteristics including sex, parental history, symptoms, and ARIA-WHO classifications. Eventually, the statistical analysis was performed by calculating frequencies.

\section{Results}

All 207 respondents in this study filled out the questionnaire forms adequately. This study revealed that the prevalence of AR among respondents were 79 out of 207 respondents $(38.2 \%)$, of which more than $60 \%$ cases involved female respondents. In addition, more than half of the AR cases have a parental history of allergic diseases (Table 1).

The AR cases were then classified according to the symptoms that they have or a history of suffering the disease. They might have chosen one or more symptoms provided in the ARIAWHO questionnaire forms. This study revealed that the most frequent symptoms were nasal obstruction and itchy nose, followed by rhinorrhea, sneezing, and eye symptoms (Table 2).

Furthermore, the prevalence of AR among respondents was categorized according to ARIA-WHO classification. Based on the duration of the symptoms, the AR cases were divided into intermittent and persistent groups; whereas based on the quality of life hampered, they were divided into mild and moderate-severe groups. This study revealed that the majority of the cases were classified as intermittent based on the duration of the symptoms and moderate-severe based on the 
Table 1 Characteristics of Respondents

\begin{tabular}{lcc}
\hline Characteristics & $\begin{array}{c}\text { Allergic Rhinitis } \\
\text { (n=79) }\end{array}$ & $\begin{array}{c}\text { Non Allergic Rhinitis } \\
\text { (n=128) }\end{array}$ \\
\hline Sex & & \\
Male & $27(34 \%)$ & $50(39.1 \%)$ \\
Female & $52(66 \%)$ & $78(60.9 \%)$ \\
Parental history & & \\
$\quad$ Mother or father & $34(43 \%)$ & $14(10.9 \%)$ \\
Both parents & $9(11 \%)$ & $2(1.6 \%)$ \\
No history & $36(46 \%)$ & $112(87.5 \%)$ \\
Total & $79(38.2 \%)$ & $128(61.8 \%)$ \\
\hline
\end{tabular}

quality of life hampered (Table 3).

\section{Discussion}

It was found that the prevalence rate of allergic rhinitis (AR) among respondents in this study was $38.2 \%$, which is within the estimated range for Asian population. World Allergy Report 2008 reported that in many parts of Asia, especially in low- and middleincome countries, the prevalence rate of $A R$ has increased from $5 \%$ to $45 \%$ as the society is being modernized. ${ }^{6}$ However, it was found that the actual number varied between countries. For example in the Philippines, the overall prevalence of AR among adults based on the 2008 National Nutrition and Health Survey was $20.0 \%{ }^{8}$ Another study conducted in Jaipur City, India showed that the prevalence of AR among school-children there was 33.5\%. ${ }^{9}$ Meanwhile, the result obtained in this study was actually slightly higher than the estimated range of the global population. The WAO reported that AR is a common disease affecting an estimate of $10-30 \%$ population globally. ${ }^{2}$

Until recently, the prevalence rate of AR among adults in Indonesia is still unknown. In
Bandung, however, there were $7 \%$ perennial AR cases in the age group of more than 10 years old. ${ }^{10}$ The discrepancy of the result obtained in the current study compared to the global estimate can be due to the study design used. This study was a questionnaire only-based survey. The ARIA-WHO questionnaire has actually been widely used as a screening test for AR in many studies due to its high sensitivity. A study conducted in Korea concluded that the questionnaire showed better validity compared to the conventional ones. ${ }^{3}$ However, it was found that the specificity of the questionnaire was not really high, so there might be many false positives included in the results. ${ }^{11}$ Thorough examinations comprising physical examination and diagnostic testing would yield a better and more accurate result. ${ }^{1}$

Another result of this study was the fact that the prevalence of AR among female respondents and male respondents was $66 \%$ and $34 \%$, respectively. This is relevant to a study done by Asha'ari et al. ${ }^{12}$ who found that $61.1 \%$ of newly-diagnosed AR cases in Malaysia involve female patients. Likewise, some studies conducted in Dr. Hasan Sadikin General Hospital Bandung also present similar

Table 2 Frequency of the Identifiable Symptoms

\begin{tabular}{lc}
\hline \multicolumn{1}{c}{ Identifiable symptoms } & Number of respondents (percentage) \\
\hline Nasal obstruction* & $71 / 79(90 \%)$ \\
Itchy nose & $71 / 79(90 \%)$ \\
Rhinorrhea** & $70 / 79(89 \%)$ \\
Sneezing\# & $65 / 79(82 \%)$ \\
Eye symptoms\#\# & $49 / 79(62 \%)$ \\
\hline
\end{tabular}

Note: The respondents may have chosen more than 1 symptom provided in the ARIA-WHO questionnaire. ${ }^{*}$ Feeling of being unable to breathe through nose **Watery, runny nose \#Violent and in bouts \#\#Watery, red itchy eyes 
Table 3 Prevalence of Allergic Rhinitis based on ARIA-WHO Classification

\begin{tabular}{|c|c|}
\hline Classification & Number of cases (percentage) \\
\hline \multicolumn{2}{|l|}{ Based on duration } \\
\hline Intermittent* & $72(91 \%)$ \\
\hline Persistent** & $7(9 \%)$ \\
\hline \multicolumn{2}{|l|}{ Based on quality of life hampered } \\
\hline Mild\# & $23(29 \%)$ \\
\hline Moderate-severe\#\# & $56(71 \%)$ \\
\hline Total & $79(100 \%)$ \\
\hline
\end{tabular}

findings, Sudiro ${ }^{13}$ found that $55.3 \%$ of the AR cases involved female and, one year later, Syukrie $^{7}$ found $61.0 \%$ also involved female patients. Moreover, $60.3 \%$ of AR cases detected among citizens in Taif, Saudi Arabia ${ }^{14}$ involved females as well. Hence, the high proportion of AR cases among women should be analyzed further to assess whether they are more prone to have AR compared to men. The result showing more female cases in this study could be due to the disproportionate distribution of the subjects. A total of 130 (62.8\%) female subjects out of the 207 respondents were invited to participate in this study, so the result in this study could have been exaggeratedly reported in this regard.

In the present study, more than half of the AR cases have a parental history of allergic diseases, such as asthma, atopic dermatitis, or AR itself. A Western Europe-based survey in 2004 showed that there were $68.1 \%$ of AR diagnosed patients who reported of having a family history of any allergic conditions. ${ }^{15}$ Asha'ari et al. ${ }^{12}$ also found that $54.4 \%$ of AR patients in Malaysia had a family history of allergic diseases. Meanwhile, Syukrie ${ }^{7}$ found that $50.4 \%$ of AR patients in Dr. Hasan Sadikin General Hospital Bandung also had a positive family history. It has long been known that the genetic background is one of the most important factors for developing any allergic diseases. ${ }^{1}$ A child with one atopic parent would possess a $30 \%$ risk of having allergic diseases, whereas a child with both atopic parents would possess an additional 20\% risk. ${ }^{16}$ Furthermore, a study conducted by Tamay et al. ${ }^{17}$ in Istambul, Turkey showed that a child with a positive family history carried a greater risk for developing AR.

The present study applied the ARIA-WHO guidelines to define the diagnostic criteria for AR, which are characterized by having two or more nasal symptoms. ${ }^{9}$ Other conditions that can be presence include eye symptoms.

The ARIA-WHO questionnaire makes it possible for the respondents to choose more than one symptom that they have or have a history of suffering from. Long ${ }^{18}$ conducted a survey on 1,000 AR patients and found that the majority experienced nasal obstruction (85\%), followed by sneezing (63\%), eye itchiness $(60 \%)$, rhinorrhea $(56 \%)$, watery eyes $(51 \%)$ and nasal itchiness (41\%). Saini, 9 on the other hand, found that the most frequent symptom was nasal obstruction (48.6\%), followed by rhinorrhea (33.0\%), sneezing (24.1\%), and itchy nose (20.3\%). Another study conducted in Boshroye, Iran ${ }^{19}$ found that rhinorrhea was the most prevalent symptom among atopic group (33\%), followed by sneezing (33\%), nasal obstruction (28.8\%), itchy nose and eyes (18.0\%), and other eye symptoms.

In the presentstudy, however, it was revealed that nasal obstruction and itchy nose were the highest presenting symptoms (90\%), followed by rhinorrhea $(90 \%)$, sneezing (82\%), and eye symptoms $(62 \%)$. The discrepancy of each study is most likely due to common variations of symptoms within AR patients.

The ARIA-WHO guidelines were also used as the classification system based on the duration of the symptoms and the quality of life hampered. ${ }^{1}$ The majority of the AR cases in some of the previous studies fell into persistent group.,12 Interestingly, more than $90 \%$ of the AR cases in the present study were in the intermittent group, similar to a study carried out in Jaipur City, India, ${ }^{9}$ although in a much lower percentage. This contrast is most likely due to the different subjects involved 
in each study. The aforementioned studies involved AR patients who came to the hospital, and there would be a high possibility that they had persistent symptoms so they needed immediate medical interventions. This could also be due to the inconsistency in filling out the questionnaire form. The respondents might not be aware that the symptoms they encountered were in fact more long-lasting.

Based on the quality of life hampered, the majority of the AR cases fell into the moderatesevere group, which is similar to most studies. ${ }^{7,9,12}$ Moderate-severe is characterized by several conditions such as abnormal sleep, impairment of daily activities, abnormal work/school, or troublesome symptoms. ${ }^{1}$ The respondents who participated in this study were students who stay mostly in Bandung and nearby areas, in which the weather and humidity are suitable for the growth and development of dust mites, commonly Dermatophagoides pteronyssinus (Der p). ${ }^{1}$ Therefore, it is probable that the subjects have been frequently exposed to the dust mite species. Furthermore, the subjects involved in this study were all students and relatively do not have time to do sports or exercises and thus increases the risk to hamper their quality of life. It is known that doing a regular exercise could balance the type 1 and type $2 \mathrm{~T}$ helper cells (also known as Th1 and Th2 cells, respectively) so the hypersensitivity effect would be less severe. ${ }^{20}$

In conclusion, the prevalence rate obtained in the present study is within the estimated range of Asian population. Some of the characteristics of the AR cases, including sex, parental history, and ARIA-WHO classification were also considered to be relevant to most studies. Since this was a questionnaire onlybased survey, further studies that include thorough examinations including physical examination and diagnostic testing would yield a better result on this matter.

\section{References}

1. Bousquet J, Khaltaev N, Cruz AA, Denburg J, Fokkens WJ, Togias A, et al. Allergic rhinitis and its impact on asthma (ARIA) 2008 update (in collaboration with the World Health Organization, GA(2)LEN and AllerGen). Allergy. 2008;63(S86):8-160.

2. Pawankar R, Canonica GW, Holgate ST, Lockey RF, editors. World Allergy Organization (WAO) White Book on Allergy 2011-2012: executive summary. Milwaukee: WA0; 2011.
3. Chung YJ, Cho IK, Lee KI, Bae SH, Lee JW, Chung PS, et al. Seasonal specificity of seasonal allergens and validation of the ARIA classification in Korea. Allergy Asthma Immunol Res. 2013;5(2):75-80.

4. Camelo-Nunes IC, Sole D. Allergic rhinitis: indicators of quality of life. J Bras Pneumol. 2010;36(1):124-33.

5. Meltzer EO, Szwarcberg J, Pill MW. Allergic rhinitis, asthma, and rhinosinusitis: diseases of the integrated airway. J Manag Care Pharm. 2004;10(4):310-7.

6. Pawankar R, Baena-Cagnani CE, Bousquet J, Canonica GW, Cruz AA, Kaliner MA, et al. State of world allergy report 2008: allergy and chronic respiratory diseases. World Allergy Organ J. 2008;1(6 Suppl):4-17.

7. Syukrie A. Hubungan antara klasifikasi ARIA-WHO 2008 dengan hasil tes kulit tusuk pada penderita rinitis alergi yang berobat di Bagian Ilmu Kesehatan THTKL RSHS/FK Unpad Periode 2010 [thesis]. Bandung: Universitas Padjadjaran; 2011.

8. Abong JM, Kwong SL, Alava HD, Castor MA, De Leon JC. Prevalence of allergic rhinitis in Filipino adults based on the National Nutrition and Health Survey 2008. Asia Pac Allergy. 2012;2:129-35.

9. Saini A, Gupta M, Sharma BS, Kakkar M, Chaturvedy G. Rhinitis, sinusitis and ocular disease-2085. Prevalence of allergic rhinitis in urban school children, Jaipur City, India. World Allergy Organ J. 2013;6(Suppl 1):164.

10. Sudiro M, Madiadipoera TH, Purwanto B. Eosinofil kerokan mukosa hidung sebagai diagnostik rinitis alergi. MKB. 2010;42(1):6-11.

11. Hojo M, Ohta K, Iikura M, Mizutani T, Hirashima J, Sugiyama H. Clinical usefulness of a guideline-based screening tool for the diagnosis of allergic rhinitis in asthmatics: the self assessment of allergic rhinitis and asthma questionnaire. Respirology. 2013;18(6):1016-21.

12. Asha'ari ZA, Yusof S, Ismail R, Che Hussin CM. Clinical features of allergic rhinitis and skin prick test analysis based on the ARIA classification: a preliminary study in Malaysia. Ann Acad Med Singapore. 2010;39(8):619-24.

13. Sudiro M. Karakteristik penderita rinitis alergi di Bagian I. Kes THT-KL RS Dr. Hasan Sadikin Bandung/FK UNPAD Tahun 20072009. Proceeding of Kongres Nasional PERHATI-KL XV; 2010 Jul 7-9; Makassar. Makassar: Balai Penerbitan Universitas Hasanuddin; 2010. 
14. Sabry EY. Prevalence of allergic diseases in a sample of Taif citizens assessed by an original Arabic questionnaire (phase I) A pioneer study in Saudi Arabia. Allergol Immunopathol (Madr). 2011;39(2):96105.

15. Bauchau V, Durham SR. Prevalence and rate of diagnosis of allergic rhinitis in Europe. Eur Respi J. 2004;24(5):758-64.

16. Male DK, Brostoff J, Roth DB. Immunology. 8th ed. Philadelphia: Saunders Elsevier; 2006.

17. Tamay Z, Akcay A, Ones U, Guler N, Kilic G, Zencir M. Prevalence and risk factors for allergic rhinitis in primary school children. Int J Pediatr Otorhinolaryngol.
2007;71(3):463-71.

18. Long AA. Findings from a 1000-patient internet-based survey assessing the impact of morning symptoms on individuals with allergic rhinitis. Clin Ther. 2007;29(2):342-51.

19. Fereidouni M, Abolhasani A, Vahedi F, Shakeri MT, Varasteh A. A preliminary survey of the prevalence of allergic disorders in a questionnaire-based study in Boshroye, a rural area of Iran. J Public Health. 2010;18(2):119-21.

20. Kidd P. Th1/Th2 balance: the hypothesis, its limitations, and implications for health and disease. Altern Med Rev. 2003; 8(3):223-46. 